GLEX-2021,12,3,1,x63014

\title{
Space exploration and the imaginaries of living in a climate-changing world*
}

\begin{abstract}
Anna Szolucha
(*paper presented at the Global Space Exploration GLEX 2021 conference in St Petersburg, Russian Federation, 2021, version of record published in GLEX 2021 Conference proceedings available from: https://iafastro.directory/iac/proceedings/GLEX-2021/)
\end{abstract}

\begin{abstract}
Over the years, space exploration has proved to possess an extraordinary potential for changing environmental perspectives on Earth. However, this ability of space to create new relationships with our own planet and to inspire narratives of environmental conservationism and climate action is undergoing a major transformation as a few spacefaring nations and commercial entities are unveiling plans to exploit extraterrestrial resources and set up space settlements. Today's space exploration is very likely to stimulate technological inventions and new ways of thinking about, relating to and acting on the climate crisis on Earth. It is also generating new imaginaries of climate change and resource extraction on other planets which could help humans become "a multi-planetary species". The cultural and sociotechnical assumptions underpinning current space endeavours are likely to shape social and environmental relations for years to come and enhance or hinder new possibilities for tackling climate change. However, we know little about how the current wave of space exploration is being culturally and socially produced and with what effects. In this article, the main premises and questions of my new research are introduced. The project explores the changing imaginaries of living from an anthropological perspective. It also uses ethnographic methods to study how three main groups of stakeholders across all continents (space scientists, activists and communities living in the vicinity of space installations) imagine life and living in the challenging environmental conditions of this and other worlds. Our new research focuses on climate change and resource extraction to analyse how people make sense of unfamiliar worlds and whether learning about these worlds can reshape how they think about
\end{abstract}


their immediate environments. To accomplish this, it also develops a new ethnographic tool of "planetary ethnography".

Keywords: imaginaries, resource extraction, environment, climate change, space anthropology, planetary ethnography

\section{Introduction}

During his last press conference from the International Space Station - after spending almost a year in space - astronaut Scott Kelly told his listeners: "The more I look at Earth and certain parts of Earth, the more I feel more of an environmentalist". "There are definitely areas where the Earth is covered with pollution almost all the time. And it's not good for any of us. There are weather systems that I've seen while I was up here that were places that were unexpected. Storms bigger than we've seen in the past. And this is a human effect" [1]. Kelly's viewpoint is not unusual as over the years, space exploration has proved to possess an extraordinary potential for changing environmental perspectives on Earth [2-4]. However, this ability of space to create new relationships with our own planet and to inspire narratives of environmental conservationism and climate action is undergoing a major transformation as a few spacefaring nations and commercial entities are unveiling plans to exploit extraterrestrial resources and set up space settlements. Today's space exploration is very likely to stimulate technological inventions and new ways of thinking about, relating to and acting on the climate crisis on Earth. It is also generating new imaginaries of climate change and resource extraction on other planets which could help humans become "a multi-planetary species" [5]. The cultural and sociotechnical assumptions underpinning current space endeavours are likely to shape social and environmental relations for years to come and enhance or hinder new possibilities for tackling climate change. However, we know little about how the current wave of space exploration is being culturally and socially produced and with what effects.

Prompted by the - unprecedented in the last 50 years - significance and diversity of the current space exploration efforts, the most overarching questions that we are asking in this project are: where is the extraterrestrial exploration leading in environmental, social and political terms? Can the exploration of other worlds help us tackle or exacerbate our problems on Earth? How will our 
Earthly imaginaries and experience shape what we will do in space? And how can our activities in space transform the ways in which people relate to Earth and cosmos? Works from the nascent (and growing) field of space anthropology have so far concentrated largely on the study of single sites, technologies or similar groups of stakeholders. Our project builds on their strengths in (1) the cultural analysis of space exploration, but also - and for the first time - expands their focus by: (2) adopting an international and comparative perspective across different sites and groups of stakeholders and (3) using climate change and resource extraction on Earth and beyond to understand terrestrial and extraterrestrial activities and social worlds as interlinked.

The main objective of this project is to investigate how contemporary space exploration can create new imaginaries about living in a climate-changing world. We will trace the impact of technologies and concepts designed for space exploration across different sites, scales and communities on all continents.

\section{Cultural and social}

The currently evolving popular discourses of space exploration espouse many patterns familiar from the Cold War "space race", buttressed by the notions of national pride, scientific rationalism, adventurous masculinity and the frontier. The concept of the frontier is inherently cultural but, in the past, it has been paramount to the universalising dynamics of exploration and served to inspire innovation as well as replicating geopolitical power hierarchies in space and unequal social relations on Earth. However, with the maturation of India's Chandrayaan missions and China's Lunar Exploration Program, the distinctly Western and largely American notions of the frontier will have to be decentred and opened up to critical scrutiny. Commercial exploration of space and long-term space settlement plans also raise novel legal and ethical challenges and recast the traditional notions of sovereignty. These developments require us to approach the existing body of research with a new lens as we are becoming more critically aware of the deeply ingrained ideological and cultural trends that have shaped much of the state of the art on space exploration during the Cold War [6]. Anthropology and ethnographic research in particular are uniquely positioned to redirect our analytical attention away from the journalistic or ideological narratives about space towards a critical examination of how imaginaries, technologies and 
resources are being culturally and socially constructed out of the new relation that is being forged between terrestrial challenges and capacities on the one hand, and extraterrestrial potentials and constraints on the other.

\section{International and comparative}

Despite the universalising narratives about space exploration, its imaginaries and impacts vary widely across sites and scales, sometimes in ways that are not easily compatible. However, we lack multi-scale, comparative and international analyses that would explicate the differences and similarities in how people relate to and imagine space exploration. Perspectives of members of indigenous communities whose land is identified as "uninhabited" and hence easily appropriated as a site for space infrastructure, are especially missing. We know very little about the change processes that unfold when indigenous lifeworlds become entangled with the needs of national or commercial space installations and narratives [7]. What is also missing is a rigorous interpretation of the broader social and political factors behind space exploration and its international and commercial diversity. To really understand the impact of space exploration and its relation to the imaginaries of living in a climate-changing world and beyond, our team will analyse the sometimes-conflicting meanings of space exploration at various sites and scales. We will also treat it as part of broader socio-political and cultural forces, not as a self-enclosed phenomenon, as was often the case with the early space historiography.

\section{Interlinked}

Climate change and resource extraction both create worlds. However, climate change on Earth means something different than on Mars, where it would be a consequence of terraforming - a process that deliberately changes a planetary environment to create more rather than less habitable conditions for human life. Despite many popular and business imaginaries, the main resource extracted on the Moon may be water rather than expensive metals or fuels. Hence, even though climate change and extraction are two ways in which imaginaries of space exploration are interlinked with Earthly experiences, they are different processes on Earth than on Mars or Moon. Our project puts that paradox centre stage to understand how people make sense of unfamiliar worlds and whether learning about these worlds can reshape how they think about their immediate environments. 


\section{Project's significance and state of the art}

\section{Cultural and social}

We now know that the Apollo decision to send humans to the Moon can be seen as an anomaly in the history of the US space programme [8]. NASA is currently preparing an even more ambitious project - called Artemis - a spaceflight programme which aims to land "the first woman and the next man" on the Moon by 2024 and then send humans to Mars. India has launched its Chandrayaan missions to explore the Moon. If Apollo was an anomaly and not a logical development step of space research in the US, we need to ask what role do Artemis or India's missions play today? Can they be understood as symptomatic of a particular socio-political and environmental moment? How will the decisions to launch these programmes enhance more than just our knowledge of the Moon's resources?

There are many approaches to space exploration and state-of-the-art literature is divided over how we should make sense of these enormous endeavours. Many historians of the American spaceflight have usually framed their work in one or more of the four main narratives based on: the "frontier" (whether as human destiny or scientific discovery), competition, technology and the astronauts $[6,9,10]$. Some wrote about space exploration as a natural outcome of the Americans' pursuit to explore the frontier (from the American frontier in the West to the space frontier beyond Earth); some interpreted it as part of a larger contest between geopolitical empires or good and evil; it was also seen as a technologically-driven enterprise or one where the astronauts were the main heroes. Many of these frames resonate strongly with popular and journalistic ways of narrating today's space exploration efforts. However, what is missing is a rigorous interpretation of the broader social, environmental and political factors behind space exploration and its cultural and commercial diversity.

Space anthropology (for very good reasons) has so far concentrated mostly on the perspectives of scientists and those who create the ideas and technologies of space exploration. Space history is also often written from the perspective of astronauts, scientists and engineers (although this is changing). This means that space history is more often an intellectual rather than a social and cultural history. One of the reasons why we have not yet closed this gap is perhaps that for many 
scientists, there may not be a lot of difference between science and exploration. However, as historians of American spaceflight have documented, it was precisely the idea of manned exploration rather than science that justified Kennedy's decision to put people into space which subsequently, captured the imagination of millions around the world. This shows that exploration is a very powerful conceptual construct, but its study remains typically fragmented by discipline and the type of technological or scientific development that we are studying. Regardless of the field, however, it usually conjures up images of progress, inspires awe as well as egalitarian imaginaries of freedom and universal prosperity. At the same time, it connotes imperialism and colonialism as well as notions of masculinist bravado and conquest. Whatever the times, exploration is a product of its social and cultural context and thus, can be an excellent indicator of the shifting social forces and dynamics as well as anticipating and shaping future developments. But how to study exploration in a way that pins down its expansive geography and geology as well as its dynamic and socially constructed character? How to wrestle with its conflicting cultural meanings? How to operationalise this concept in a way that makes it useful for tackling the most important Earthly challenges? Exploration is fraught with many productive tensions, between private and public, familiar and unfamiliar and between cultural and universal. By bringing these tensions to the fore and thinking across different worlds - using "planetary ethnography" (see section 3 on methodology) - in this project we are best positioned to uncover the emerging social and cultural forces that will help us explain shifts in the ways people around the planet relate to space exploration and imagine living on Earth and beyond it. Our social and cultural focus will help us redirect attention away from the traditional and romanticised notions of space exploration to the relation between different socio-political and cultural formations, trends and beliefs on the one hand, and a magnitude of cultural, technological and conceptual developments associated with contemporary space missions on the other.

If we accept that exploration works as a cultural concept, then space exploration needs to be understood as culturally produced. The values associated with exploration today are different from those 50-60 years ago. But what are these new values today and why do people in various cultural contexts find them desirable? It also remains underexplored how memory, nostalgia, image making and myth shape our understandings of exploration efforts $[6,11]$. We do not know what role fake news, popular culture and political populism play in shaping popular conceptions 
of contemporary exploration. Are the new commercial ventures in space creating a new identity, form of citizenship or autonomy? In our project, we will examine the connections and impacts that these new developments in broader social and cultural forces have on space exploration. Are they really leading to the creation of a "multi-planetary" species, as some NewSpace entrepreneurs tout it? If so, who is included and excluded from this vision? These are all pertinent questions that need to be researched in real-world settings but they often escape the scope of a lot of popular writing and a sizeable share of nonanthropological research on contemporary space exploration. Thanks to our project, we will be able to present a critical analysis of the social, cultural, environmental and political factors that are shaping the needs and underlying assumptions of contemporary space activities. Importantly, we will also be in a position to identify any cultural models of society that may be embedded in some space technologies and analyse who could benefit from such models and who would bear their main burden.

In this context, we will be able to draw, but also revisit and significantly expand, on research of such space anthropologists as David Valentine [12] who worked with NewSpace entrepreneurs. He argued that NewSpace ventures should not be understood as merely the latest version of neoliberal capitalism that aims to enrich certain people, this time expanding the scope of their commercial activity into space. Instead, his research takes seriously NewSpace's, apparently extreme, visions of capitalism and human futures and shows "how powerful social actors shape deep human futures through cosmological commitments to radical views of what it is to be human... the practices of powerful social actors should not be reduced to the abstracted workings of 'the market' but rather, to be fully understood, they must be considered as social, ideological, but also cosmological" [12]. Through our social and cultural analysis, we will be able to answer new questions posed by the recent rise of NewSpace entrepreneurs like Elon Musk and his SpaceX programme. They challenge the history of nationally-defined objectives for the human exploration of extreme places and resources. However, the narratives that they promote are also very similar to the earlier waves of spaceflight in that they too make claims about space exploration as a global and universal normative [13]. Like Valentine, we will take these claims seriously, but we will also compare and contrast them with the ways in which other, often less powerful actors, imagine and experience space exploration. This will help us get a fuller picture of the social and cultural construction of space exploration efforts and will also allow us to 
understand their relation to other actors and the broader social, political and environmental contexts. The timing of our project aligns perfectly with the main schedule of NASA's, India's and many other space exploration efforts. Hence, we will be in a unique position to ethnographically study these important developments as they unfold in real time and work with people who are directly involved.

Our cultural deconstruction of exploration would not be complete without questioning the terrestrial presumptions of our theories. Several space anthropologists have advocated expanding and reorienting our analytical gaze to look for places that matter outside of our own planet $[14,15]$. In line with this suggestion, we conceive of space as a thoroughly (extra)social environment, where humans and machines in space co-generate and project specific values and relations that are capable of being translated into our Earthly settings. We hypothesise that we no longer just imagine other worlds in outer space; rather, these worlds are beginning to feed back images and narratives that can influence how we think about and engage with our planet. These narratives will be rich in implications and may require that our terrestrial theories undergo a significant transformation as a result.

\section{International and comparative}

Space exploration is a scientific and technological practice but it is also a subject of international public debate and engagement. It is in tandem with these popular forces that exploration can transform various places and resources from material objects into social, economic and political potential. However, many historical narratives of spaceflight have portrayed space exploration as an inevitable outcome of political, national or ideological forces that were consistent on all levels. As Asif A. Siddiqi [16] demonstrates in his research about the birth of the Soviet space programme, this image may often be inaccurate. In the Soviet Union, the origins of the space programme have to be identified in the "science from below" - a persistent, difficult and often unrewarding effort of various intellectuals and engineers fuelled by particular cultural and religious trends of the time as well as the public's general interest in space matters. This example shows that we cannot assume that the aims and imaginaries of space exploration are always accurately defined by the dominant narratives or the most powerful groups of stakeholders. Hence, in this project, we will work with three main groups of stakeholders on all continents to 
examine how exploration navigates the social forces in the private and public realms across different national contexts. The three groups of stakeholders are: (1) space scientists and engineers who develop tools and concepts for current space missions, (2) space activists and lobbyists who advocate new directions in space exploration and (3) communities living near space installations. The advocates of space exploration tout it as an opportunity for the humanity to become a multi-planetary species (i.e. for humans to live on more than one planet). In this context, our multiscalar approach is unique because it accepts that our researched communities may already be "multi-planetary" - they are living in different planetary worlds through their work, imaginaries or ways in which their daily routines and aspirations are impacted by the operation of space infrastructure and planetary movements.

Historically, the frontier is the concept that has captured a lot of political and corporate imagination about space. However, the multiscalar design of our research recognises that there are serious problems with imagining a frontier as an empty space [17]. Exploration broadens the scope of what counts as human and social environment - both on and beyond Earth [18]. Yet, the frontier - the very place where exploration takes place - is often enmeshed in exclusionary dynamics. By definition, the frontier is a place with certain dangerous or extreme characteristics that the chosen few explore for the purported benefit of others. The frontier, therefore, has its own politics and sociality that may be at odds with its broader social and political objectives. The utopian dreams of better environmental living, which may work at the frontier, do not automatically bring about social justice outside of it. This is why in this project, we aim to link the imaginaries and impacts of space exploration with their social, cultural and political contexts at various scales and places. We aim to bring together scientists, industry, local residents and social movements to experience space exploration as a lived infrastructure and a social process. This will help us build a systemic view of space exploration and create productive tensions worthy of further research.

I want to acknowledge that exclusionary and imperialist dynamics persist in the language and practice of space exploration; but there is a difference between acknowledging the fact and assuming that it is an inherent feature of the process, especially since many actors (such as space scientists) will certainly not experience exploration in this way. Critical social science has shown 
how the frontier is socially constructed as an expanding technological zone [19] that universalises certain economic and political logics, a physical and social enclave [20], or a form of offshore modularity [21] which is not only highly mobile but also effective in privatising and internalising the value of a local resource. Expert knowledge is central to these processes but the understanding of the role that scientists play in doing political work is often developed about rather with them. My experience of working in interdisciplinary research programmes on unconventional resources shows that many experts are indeed interested in and receptive to a social analysis of the work that they are doing. They feel uneasy about the potential negative impacts of their job and would like to know how their expertise bears on real-world problems within as well as outside their field. Hence, in this project, we do not only analyse but also destabilise the exclusionary dynamics of the frontier by both opening it up to its lived social context and looking inside the labs themselves to understand how the frontier may be built into the very models and tools that scientists are developing. Can the frontier gather rather than exclude? Can we use it as a point of productive friction rather than exclusionary order?

The paradox of the frontier has been that it is deeply embedded in governmental, military or commercial projects and funding; yet it often spurs egalitarian and idyllic imaginaries of peace and democracy. The contemporary lunar and Mars missions play on this theme of making other places unlike (better than) our planet. The goal is not only to escape the confines of the environmentally troubled Earth but also to stay outside it. However, in order to achieve selfsustaining space settlements, people living on other celestial bodies would have to utilise extraterrestrial resources. Staying away from Earth, therefore, requires a thoroughly terrestrial practice of resource exploration. Will the space frontier be able to reconfigure the terrestrial practices of resource exploration away from its exclusionary and alienating dynamics? How will this exploration be governed? What social dynamics and impacts will it create? Will the very strict management process for space exploration and landings generate novel concepts of living on our planet or innovations around notions of property, environmental impact and waste? Will we all be asked to live like astronauts in their cabin-ecology systems (see section 2.3.1 below)? Or can the localised images of the lunar and Mars surfaces with their texture and landscapes, reframe how we see Earth? Can the fact that water will have to be mined on the Moon and will not only be necessary for breathing and drinking, but will also constitute rocket fuel, influence 
our imaginaries of this resource and its increasing volatility on Earth? Or will extraterrestrial resources justify an even more extensive exploitation of resources on Earth?

To answer these and other pertinent questions, we adopt a robustly international and comparative perspective because space exploration is often justified referring to universally-sounding, but nationally specific understandings of modernity, progress and social justice [13]. One of the characteristics of the exploration paradigm is that it is a cultural force that universalises and legitimises certain culturally-specific logics. Although some researchers have signalled the potential problems with conceiving of exploration as universally good [22], comparative and multiscalar research is required to understand whether the perception of scientific elites - who define the narratives of space exploration - may be at odds with other understandings of both exploration and science. In our project, we will use multiscalar research in different countries to explore the use of scientific metaphors in contexts where specific scientific and national values and principles have less purchase than other ways of building social worlds. For this purpose, I will conduct research in communities living near space installations in the USA and India and other team members will investigate other contexts where space exploration is given meaning in relation to cultural forces other than just the post-Enlightenment Western scientisation of society.

\section{Interlinked}

Lisa Messeri who worked with exoplanet scientists wrote about their practices of place- and world-making that entangled Earth with the unfamiliar worlds of other planets: "Ideas of what it means to be on Earth shape studies of other planets, and studying the habitability of other worlds refines how we define life on Earth" [22]. This entanglement of different worlds is characteristic of many studies in space anthropology. Valerie Olson [18], for example, shows how spaceflight "systems", including spacesuits and analogue missions in extreme Earthly environments, are aimed at making connections or changing relations to the outer space environment. Although space anthropologists do make references to climate change and resource extraction in the context of space exploration, they have not yet been systematically analysed as interlinked social and cultural phenomena ${ }^{a}$. At the same time, popular imaginaries of living on other bodies or structures in space due to a climatic apocalypse on Earth are rife in popular culture, among space activists and some scientists. Their interest in space resources such as water or various metals 
also largely stems from science fiction visions of living on other planets. However, it is difficult to imagine a government-funded space research programme that would be simply aimed at creating the possibilities for leaving the Earth permanently. Instead, while many space technologies are directed at other worlds, they are also rooted in typically earthbound problems. In this project, for the first time, we stitch together these seemingly separate worlds of space exploration, climate change and resource extraction. We use an internationally comparative perspective to understand whether connecting terrestrial processes with extraterrestrial imaginaries and space technologies can decentre our earthbound view and change the ways in which we relate to living on Earth.

I see space exploration, climate change and resource development as inherently interlinked in the way in which: (1) space science has contributed to climate science and ecology, for example through imaginaries of life in space cabins and the "Spaceship Earth"; (2) ventures in space as well as Earthly resource extraction share an analogous preoccupation with technologies and materialities of resources as well as similar narratives of exploration, frontier and the extreme; (3) they have a great capacity to capture people's imaginations and activate a strong affective response; and (4) they carry significant cultural charge and are mutually socially constructed. Below, I expand on each of these aspects, building on the existing literature.

\section{Space activity has been a model for ecological living on Earth}

The "Earth Day Proclamation" of 1970 - an important moment in the evolution of American and international environmentalism - cites space exploration as the foundation of a "new world view" that was emerging "through the eyes of our Astronauts and Cosmonauts". The importance that was attributed to this new perspective cannot be dismissed as political rhetoric. Beginning with the US space programme in the 1960s, the ideas of leading ecologists working on the construction of closed ecological systems such as space capsules, began to percolate into universities, conferences and countercultural milieus and then came to shape the managerial imaginaries of climate science.

The beginnings of "cabin ecology" can be traced back to the 1950s, when astronautics scholars believed that space cabins should be built in a way that closely resembled earthly environments. 
This particular research was funded by the military which considered it useful for understanding how to design submarines or atomic shelters. The challenge was revived in the 1960s when the United States committed themselves to the exploration of the Moon. Ecologists who got involved in this effort created a number of conceptual and semiotic devices such as "carrying capacity" and the "Spaceship Earth" which were later adopted as part of the international ecological vernacular, discourse and ethics. State-of-the-art historical research shows how "Technology, terminology, and methodology developed for ecological colonization of space became tools for solving environmental problems on Earth" [23].

In popularising space technologies such as solar cells, energy-saving devices and recycling, their advocates did not only shape Earthly practices in light of the planet's finite resources, but they also created a particular understanding of ecosystems on Earth that demanded a specific ethical response [9]. The planet's limited carrying capacity (originally, the ability of a spaceship to support a given number of astronauts) required a strict scientific management of the population on the Spaceship Earth. Later NASA sponsored or partnered in projects that expanded that vision by imagining space stations as entire ecosystems which rescued and preserved the Earth's most desirable elements and species from their ecological destruction. Cabin ecology contributed to the remodelling of sustainable living on Earth. Managerial ideas, scientific rationalism and technological determinism that governed activities and imaginaries of space exploration have also become standard measures for the organisation of society, its environmental ethics and spatial politics [14].

The influence of that space-cabin perspective lingers to this day and beyond the American context. For example, the EU sees the role of social sciences in responding to the climate challenge in terms characteristic of space cabin management, providing solutions in food diet, mobility services and energy consumption "to promote living-lab experiments on ways to boost the zero-carbon economy" [24]. However, this space-cabin perspective may undergo a major transformation with the new missions that can involve resource exploitation on another celestial body. This will likely produce images other than the small, blue marble that we know of thanks to the earlier missions. Instead, we will probably see more very localised images of the Moon that will show the texture, colour and a detailed landscape of the surface. How would these images 
influence the way we will view Earth? How will our Earthly resource exploration technologies and dynamics fare in space? Finally, how will the concurrent attempts by a few spacefaring nations to explore the Moon's surface impact on the traditional imperial terminology associated with space colonisation and space colonies?

\section{Extreme environments on Earth and in outer space are connected}

Space and resource exploration share a common vocabulary and imaginaries of extremes, frontiers and exceptions. In my research so far, I have analysed how the construction of shale gas as an unconventional resource has more than merely technological implications. The constructed unconventionality of shale helped to secure an exceptional political status for the resource and dis-embedded shale gas from social and environmental relations. Resource environments whether on Earth or in space - are often perceived as such unconventional extremes. The category of the extreme blends the severe material conditions of exploration with "a mode of power, and a state of being and potential that is outside and always subject to another boundary beyond" [25].

Social research on Earthly extraction has produced largely critical accounts of the frontier as a place of "complex processes of dispossession, compromise, violence, and engagement" [26]. Linking the conversations in social sciences on resource extraction (across several disciplines and including the nascent energy anthropology) with the emerging field of space anthropology is not only viable but also necessary. "Space sciences" can enrich "resource sciences" by opening them up to a critical assessment of the role of national identities in the cultural production of resource frontiers. "Resource sciences" can assist "space sciences" in developing a more detailed understanding of the balance of benefits and burdens that exploration produces across populations and environments.

Space exploration has already had the power to shift disciplinary domains. In astronauts' training, various geological sites on Earth have become an analogue to the lunar landscape, which has reworked the Moon from being a solely astronomical object to a geological object [27]. The planned expansion of the human activity on the Moon and beyond, can make an even stronger case for understanding outer space as an (extra)social object and this would signify a profound change in our earthbound worldviews. 
Space and resources capture popular imagination and bring about change

In my research on unconventional resources, I have learned that resource exploration has enormous, almost magical, powers to create images of bountiful futures, even if the resource has not been confirmed. The anticipatory politics of resource extraction draws on historical tropes of industrial heroism and geopolitical contest. The American space programme and the Apollo landings, and, in the other bloc, Gagarin and Sputnik also stirred the imagination of nations. The conceptions of space exploration in popular culture, in turn, shaped national space policies [6] and imbued them with universal meanings of ideological, logistical and moral superiority. Space exploration like resource extraction has an extraordinary ability to seize on the most powerful mythologies and cultural tropes to inspire and mobilise populations as well as justify particular political choices. Hence, it is probable that developments in space exploration will also have an impact on the most pressing environmental challenges at the present historical juncture.

Furthermore, using space as a model for tackling Earthly challenges is, in fact, what spacefaring states entice others to do. Whether it is the image of the frontier as in America, or the philosophy of Cosmism and industrial communism as in Russia, or a particular form of postcolonial sovereignty mobilised for the welfare of the population as in India [13], they are deeply cultural ways through which nations realise goals that - they claim - have universal significance. Our project will be able to examine whether this is more than a rhetorical device.

Finally, the emerging trends in climate change response give us reasonable grounds to think that the current wave of space exploration will be able to mobilise significant changes in institutions, technologies and popular culture even without the context of the Cold-War rivalry. Climate change is increasingly seen by some corporations, elites and the military as a new adversary $[28,29]$ that may replace the conflicted political blocs as a new source of existential threat that has spurred so many changes over half a century ago.

Exploration everywhere is socially constructed 
The emerging literature on resource-making [30,31] and place-making in space [22] highlights the social construction of resources and environments. Resources are not given objects but relational effects that are transient, distributed and nonlinear categories which take shape in sometimes contentious ontological and political contexts. Similarly, social sciences informed by their relation to space (and space anthropology, in particular) can "open to the ways in which Earth and space are connected through non-living spatial, environmental, and ecological connections, and provoke new ways of seeing terrestrial arrangements and imagining how they may work out in space-without presuming their outcomes" [14].

The development of these approaches helps our project to move between and across fields and scales to enhance our perspective about the mutual dependencies, contradictions and tensions between space exploration, resource-making and climate change. We can expand beyond the study of specific projects or artifacts to their social construction, directing particular attention to the new forces that they engage and the institutional, regulatory and cultural changes that they reflect or bring about. One area for investigation will be for example how the practices of commercial social responsibility used by the extractive industries on Earth would relate to the model for resource exploitation on an uninhabited celestial body. Would Moon exploration come to redirect Earthly extraction away from public engagement? How would the consciousness of anthropogenic climate change shape engagement with resources elsewhere?

\section{Methodology}

In this project, we will develop and employ the tools and conceptual background of a new and bespoke approach to ethnography (planetary ethnography). These tools will create new ways of exploring social phenomena on a global scale and test the limitations of the meaningful modes of interacting with objects, people and processes that lie outside of the normal bounds of human experience and agency. Our main analytical lens will be social constructivism.

\section{Planetary ethnography}

Ethnographic methods such as participant observation, interviews and surveys will help us gain an insight into the creation of emerging imaginaries, relations and technologies that will come to shape life in the climate-changing world. Through these methods, we will examine everyday interactions between people, non-human actors and their environments. This will allow us to 
analyse the social construction of activities, relationships and values that influence and are influenced by the changing environmental conditions of space exploration and climate change.

One of the characteristics of planetary ethnography is that we will employ ethnographic research across sites and scales. Multi-sited ethnography crosses the boundaries of a single field site by expanding it to several physical locations as part of a single study. Space exploration and climate change are inherently trans- and multi-local; hence, all field sites should also be understood as part of a bigger "assemblage" $[33,34]$. The multiscalar approach in our research refers to the sometimes-conflicting meanings of the same development at various scales. The attention to the multiscalar dimension of our research objectives can bring out the contradictory, yet interconnected perspectives on exploration from local, through national and international to the extra-planetary scale. The extended case method [35] and the "analysis of a social situation" [36] which relate everyday life practices and features to the broader systems of social relations, will be useful points of reference for how to employ multi-sited and multiscalar ethnographic methods in ways which are scientifically rigorous and feasible.

The innovative element of our method is in the way in which this will be planetary ethnography. Planetary ethnography, as I propose we understand it here, will encompass three elements: (1) due to the necessarily multiscalar and multi-sited nature of the researchers' individual projects, our ethnographic methods will not be limited to a bounded community, but expand our experiential ways of knowing beyond a location or a set of locations; (2) planetary ethnography will be collaborative - the team will be involved in a programme of thematic workshops that I will organise. If possible, the workshops will take place in important locations and involve local actors who have a significant connection to space exploration. The programme of a field workshop will involve discussions with local stakeholders, participation in local events and site visits. We will use these field settings to train team members, learn, challenge our research results and network to expand our analytical outlook. I will facilitate a collective publication at the end of each workshop. And most importantly for my take on planetary ethnography, (3) I invoke the planet as a new mode of knowing and experiencing inspired by Gayatri Spivak's notion of planetarity [37]. 
Planet can be an uncanny object - simultaneously within and outside of the normal bounds of human comprehension and experience. At once intangible as part of the cosmic scales and directly palpable in everyday experience. Humans are at the same time part of and outside of the natural processes on Earth and in cosmos. Planet exceeds their control and planetary thinking and ethnography aims to undo some of the familiar, abstract categories that we use to "act on climate". Planetary ethnography focuses on relations and alterity - within and between the categories of human and nonhuman, terrestrial and extraterrestrial. It observes and analyses with instead of for the planet.

Planetary ethnography will, therefore, be a process through which an interdisciplinary group of scholars and local stakeholders will not only come to shape one another's research, but - more importantly - see our individual research and expertise (whether lay or professional) as inherently related and an indispensable part of a bigger challenge. I think the method is particularly useful for identifying emerging dynamics and changing social formations as well as creating meaningful links and understanding contradictions between various social phenomena across vast distances and scales.

\section{Social constructivism}

Social constructivism will be the general theoretical approach that we will adopt in this project. This is without prejudice to other approaches such as structuralism, actor-network theory or posthumanist approaches that team members may find useful in their individual projects. The emphasis on social constructivism responds to the conceptual and political need to move beyond methodological approaches that embrace technological and other types of determinism in the context of space exploration and climate change. Instead, I propose to focus on the social construction of technologies, resources and ideas to understand how they are being encoded with new social and cultural meanings that will influence our ability to mitigate climate change. Social constructivism allows the ethnographic detail of our studies to come alive. I think it is the closest that we can get to predicting the futures of exploration and climate change in social terms.

We will seek to integrate "planetary", multi-sited ethnography and multiscalar research in ways that lay out clearly and concisely how new ideas about living in a climate-changing world are 
being socially constructed out of the challenging relationship between space exploration and the changing environmental and social conditions on Earth.

\section{Research stakeholders and sites}

The PI will conduct ethnographic research in the USA and India. Other team members will choose their fieldwork sites across other countries (so that there is at least one field site on each continent), corresponding closely to the aims and the thematic area of our overarching research programme. This will help to broaden the analytical scope of the project, create more cases for comparison and allow to build on the existing strengths of other team members.

All team members will adopt an inclusive approach which takes into consideration three main groups of stakeholders: (1) those who are involved in the creation and testing of new space tools and technologies, for example space scientists and engineers; (2) those who advocate new directions in space exploration, i.e. space activists, enthusiasts, lobbyists and NewSpace entrepreneurs; and (3) those who experience the impacts of space exploration on Earth, namely frontline communities who live and work in the vicinity of space infrastructure such as spaceflight launchpads.

\section{Project's scientific contribution}

Our research will help address gaps in space anthropology by: (1) exploring imaginaries of space exploration at various scales rather than focusing on similar stakeholders or bounded national contexts, (2) focusing on extraction and climate change to understand the interlinking between the environmental crisis on Earth and people's changing relations with outer space. The tools and concepts of "planetary ethnography" (see section 3 on methodology) that we will develop in this project will be a useful reference point for ethnographers who seek meaningful ways of researching and understanding social and natural phenomena that are beyond the normal bounds of experience such as ethnographies of extreme events or vast environments. Our research will develop important debates in the anthropology of mining and energy anthropology through its focus on the social construction of resources and fuels. In particular, it will help us understand the balance of benefits and burdens of exploration and extraction and the social dynamics that it generates, even in relation to such seemingly distant places as outer space. We will also 
contribute to the more traditional anthropological interests by using insights from the most recent developments in space technologies to shed new light on the age-old, yet immediately urgent question about the future of human beings in the world and cosmos. The current space exploration efforts are not isolated phenomena, but a product of the current cultural, social and political moment. As such, they are also useful analytical tools for examining the capacity of our current social and political structures to shape the world's future on a planetary and extraplanetary scale. By researching future space exploration in a comparative way at different sites and scales, therefore, we will also contribute to the social science's ability to explain the present social relations and hierarchies from multiple vantage points.

Our research will also make a contribution to political anthropology because I think that space exploration may even prefigure new state transformations and anticipate a new form of democratic politics. Resource exploration activities on Moon or Mars will hardly be embroiled in the same kind of democratic constraints that terrestrial resource development is on Earth. Space exploration may, therefore, produce authoritarian impacts if it comes to influence the way we imagine resource extraction and governance on our planet. Although some of the current space programmes are determined by typically national objectives, the NewSpace entrepreneurs and such projects as SpaceX may bypass the state. Our project will help to explore what impact this visible commercialisation of spaceflight will have on people's political imaginaries.

Moreover, the fundamental contribution of our project to anthropology and social sciences more broadly, will be in the way in which it will accelerate our thinking about the earthbound nature of our social theories. Imaginaries and technologies of interplanetary exploration and space settlement as well as climate change may require that our terrestrial theories undergo a significant transformation. Thinking about humans as multi-planetary beings means imagining them as a slightly different species (due to a different atmosphere and gravity of other planets which may reshape human physiology). Thinking about other planets and moons as possible settlements means imagining a social and cultural context where the world does not only mean Earth but other places as well. This decentring of our earthbound and anthropocentric perspectives opens new horizons and provokes further questions: what can multi-planetary environmental politics look like? Can a stronger affective or material relation with other celestial bodies reshape human 
identities? What new ethical questions will it provoke? Will the Earthly hegemonies and relations reinvent itself in the new conditions, perpetuating the same dynamics traditionally associated with exploration of resources and new places? The exploration of outer space may be becoming increasingly intertwined with our resource and climate futures on Earth in new and unexplored ways. Like a space cabin in the 1970s (see section 2.3.1), extraterrestrial extraction may become a new model for managing the environmental constraints on Earth. If so, modelling our terrestrial futures on the technologically-determined and highly culturally specific endeavours can influence the ways in which we tackle climate change for years to come. Space developments may come to legitimise a wide range of social and political choices and may even prefigure new forms of politics and society.

a Although it still focuses largely on the conditions of terrestrial resource extraction, the work of geographer Julie Michelle Klinger [29] on "rare earth frontiers" is a notable exception here. Her engaging book examines how Earthly politics (and powerful mischaracterisations of metals) have spurred imaginaries of a mining boom on the Moon. She also suggests that mining of rare earth metals in strangely remote or extreme places sometimes serves as a pretext for broader political or economic struggles. Her book features a map showing various locations on the globe alongside a graphic of the Moon to depict Klinger's fieldwork sites and other important locations examined in her text - an example of the interlinking of different worlds that our project will develop.

\section{Funding}

This project has received funding from the National Science Centre, Poland, project number 2020/38/E/HS3/00241.

\section{References}

[1] S. Newman, The astronaut who became an environmentalist. 11 March 2016, http://www.1millionwomen.com.au/blog/astronaut-who-became-environmentalist/,

(accessed 27.09.19).

[2] D. Cosgrove, Contested Global Visions: One-World, Whole-Earth, and the Apollo Space Photographs, Annals of the Association of American Geographers 84 (1994) 270-294. 
[3] S. Jasanoff, Image and Imagination: The Formation of Global Environmental Consciousness, in: C. A. Miller, P. Edwards (Eds.), Changing the Atmosphere: Expert Knowledge and Environmental Governance, MIT Press, 2001, pp. 309-337.

[4] C. Sagan, Pale Blue Dot: A Vision of the Human Future in Space, Ballantine Books, 1997.

[5] E. Musk, Making Humans a Multi-Planetary Species, New Space 5 (2017) 46-61.

[6] A. A. Siddiqi, American Space History: Legacies, Questions, and Opportunities for Future Research, in: S. J. Dick, R. D. Launius (Eds.), Critical Issues in the History of Spaceflight, NASA, 2006, pp. 433-480 (NASA, 2006).

[7] A. Gorman, The cultural landscape of interplanetary space, Journal of Social Archaeology 5 (2005) 85-107.

[8] R. D. Launius, H. E. McCurdy, H. E., Introduction: The Imperial Presidency in the History of Space Exploration, in: R. D. Launius, H. E. McCurdy (Eds), Spaceflight and the Myth of Presidential Leadership, University of Illinois Press, 1997, pp. 1-14.

[9] R. D. Launius, Compelling rationales for spaceflight? History and the search for relevance, in: S. J. Dick, R. D. Launius (Eds.), Critical Issues in the History of Spaceflight, NASA, 2006, pp. 37-70.

[10] D. A. Mindell, Digital Apollo: Human and Machine in Spaceflight, The MIT Press, 2011.

[11] M. E. Byrnes, Politics and Space: Image Making by NASA, Greenwood Publishing Group, 1994.

[12] D. Valentine, Exit Strategy: Profit, Cosmology, and the Future of Humans in Space, Anthropological Quarterly 85 (2012) 1045-1067.

[13] A. A. Siddiqi, Competing Technologies, National(ist) Narratives, and Universal Claims: Toward a Global History of Space Exploration, Technology and Culture 51 (2010) 425-443.

[14] D. Battaglia, D. Valentine, V. Olson, Relational Space: An Earthly Installation, Cultural Anthropology 30 (2015) 245-256.

[15] V. Olson, L. Messeri, Beyond the Anthropocene: Un-Earthing an Epoch. Environment and Society 6 (2015).

[16] A. A. Siddiqi, The Red Rockets' Glare: Spaceflight and the Soviet imagination, 1857-1957, Cambridge University Press, 2013.

[17] L. Messeri, Why We Need to Stop Talking About Space as a "Frontier". Slate Magazine. 15 March 2017, https://slate.com/technology/2017/03/why-we-need-to-stop-talking-about-space-as-afrontier.html, (accessed 11.08.20).

[18] V. Olson, Into the Extreme: U.S. Environmental Systems and Politics beyond Earth, University of Minnesota Press, 2018.

[19] A. Barry, Technological Zones, European Journal of Social Theory 9 (2006) 239-253. 
[20] G. Bowker, A Well Ordered Reality: Aspects of the Development of Schlumberger, 1920-39, Social Studies of Science 17 (1987) 611-655.

[21] H. Appel, Offshore work: Oil, modularity, and the how of capitalism in Equatorial Guinea, American Ethnologist 39 (2012) 692-709.

[22] L. Messeri, Placing outer space: an Earthly ethnography of other worlds, Duke University Press, 2016.

[23] P. Anker, The ecological colonization of space. Environmental History 10 (2005) 239-268.

[24] European Commission, In-depth analysis in support of the Commission Communication COM(2018)

773. A Clean Planet for all: A European long-term strategic vision for a prosperous, modern, competitive and climate neutral economy (2018).

[25] D. Valentine, V. A. Olson, D Battaglia, Extreme: Limits and Horizons in the Once and Future Cosmos. Anthropological Quarterly 85 (2012) 1007-1026.

[26] M. Watts, A Tale of Two Gulfs: Life, Death, and Dispossession along Two Oil Frontiers, American Quarterly 64 (2012) 437-467.

[27] L. Messeri, Earth as Analog: The Disciplinary Debate and Astronaut Training that Took Geology to the Moon, Astropolitics 12 (2014) 196-209.

[28] N. Buxton, B. Hayes (Eds.), The Secure and the Dispossessed: How the Military and Corporations Are Shaping a Climate-Changed World, Pluto Press, 2015.

[29] J. M. Klinger, Rare earth frontiers: from terrestrial subsoils to lunar landscapes, Cornell University Press, 2017.

[30] K. Kama, Resource-making controversies: knowledge, anticipatory politics and economization of unconventional fossil fuels, Progress in Human Geography 44 (2020) 333-356.

[31] T. Richardson, G. Weszkalnys, Introduction: Resource Materialities, Anthropological Quarterly 87 (2014) 5-30.

[32] A. Szolucha, A social take on unconventional resources: Materiality, alienation and the making of shale gas in Poland and the United Kingdom. Energy Research \& Social Science 57 (2019) 101254.

[33] H. Appel, A. Mason, M. Watts, Introduction: Oil Talk, in: H. Appel, A. Mason, M. Watts (Eds.), Subterranean Estates: Life Worlds of Oil and Gas, Cornell University Press, 2015, pp. 1-26.

[34] J. I. Guyer, Oil Assemblages and the Production of Confusion: Price Fluctuations in Two West African Oil-Producing Economies, in: H. Appel, A. Mason, M. Watts (Eds.), Subterranean Estates: Life Worlds of Oil and Gas, Cornell University Press, 2015, pp. 237-255.

[35] M. Burawoy, The Extended Case Method. Sociological Theory 16 (1998) 4-33.

[36] M. Gluckman, Analysis of a Social Situation in Modern Zululand. Bantu Studies 14 (1940) 1-30.

[37] G. C. Spivak, Death of a Discipline, Columbia University Press, 2003. 